\title{
HOT AND COLD WARS
}

DOI 10.15826/qr.2016.2.161

УДК 355.014(470.53)+316.485.26+323.282+929Дзержинский

\section{"ПЕРМСКАЯ КАТАСТРОФА" КРАСНОЙ АРМИИ И СТАНОВЛЕНИЕ СТРАТЕГИИ ТЕРРОРА ЖЕЛЕЗНОГО ФЕЛИКСА}

\author{
Илья Ратьковский \\ Санкт-Петербургский государственный университет, \\ Санкт-Петербург, Россия
}

\section{THE RED ARMY'S “PERM CATASTROPHE” AND IRON FELIX'S TERROR STRATEGY DEVELOPMENT*}

\author{
Ilia Ratkovsky \\ Saint Petersburg State University, \\ Saint Petersburg, Russia
}

\begin{abstract}
The article examines the circumstances of the "Perm catastrophe" in 1918. The author focuses on the consequences of the military defeat of the Third Red Army at Perm, revealing the main role of Ya. M. Sverdlov in F. E. Dzerzhinsky and Stalin's secondment to Vyatka. The result of this trip was the strengthening of Yakov Sverdlov's position, an important circumstance being Felix Dzerzhinsky's replacement by Yakov Peters. The article reveals the role of Joseph Stalin and Felix Dzerzhinsky in the investigation of the "Perm catastrophe in 1918" and their work in Vyatka and Glazov. In addition to arrests, they carried out numerous mobilization activities in the region which led to the stabilization of the Eastern Front. White terror in Perm Region had a great impact on Felix Dzerzhinsky's radicalization of attitudes. First of all, it was his attitude to the officers that changed, with him regarding officers as the main threat to the Soviet system. It resulted in his frequent orders
\end{abstract}

* Citation: Ratkovsky, I. (2016). The Red Army's "Perm Catastrophe" and Iron Felix's Terror Strategy Development. In Quaestio Rossica. Vol. 4. № 2, p. 109-118. DOI 10.15826/ qr.2016.2.161.

Цитирование: Ratkovsky I. The Red Army's "Perm Catastrophe” and Iron Felix's Terror Strategy Development // Quaestio Rossica. Vol. 4. 2016. № 2. P. 109-118. DOI 10.15826/ qr.2016.2.161 / Ратьковский И. «Пермская катастрофа» Красной армии и становление стратегии террора Железного Феликса // Quaestio Rossica. T. 4. 2016. № 2. C. 109-118. DOI 10.15826/qr.2016.2.161.

(С) Ратьковский И., 2016

Quaestio Rossica • Vol. 4 • 2016 • № 2, p. 109-118 
to execute former army officers during his time as Chairman of the Cheka (Emergency Committee).

Keywords: 1918; F. E. Dzerzhinsky; J. V. Stalin; Ya.M. Sverdlov; Ya. Kh. Peters; "Perm catastrophe"; white terror.

В статье рассматриваются обстоятельства «пермской катастрофы» 1918 г. Акцент сделан на военных последствиях поражения Третьей Красной армии под Пермью. Выявлена главная роль Я. М. Свердлова в командировании Ф. Э. Дзержинского и И. В. Сталина в Вятку. Результатом этой командировки стало усиление позиций Я. М. Свердлова. Важным обстоятельством явилась замена Ф. Э. Дзержинского на Я. Х. Петерса. Раскрывается роль И. В. Сталина и Ф. Э. Дзержинского в расследовании «Пермской катастрофы» 1918 г. Показана их деятельность в Вятке, Глазове. Помимо арестов, они провели многочисленные мобилизационные мероприятия в регионе. Результатом их деятельности стала стабилизация Восточного фронта. По мнению автора, белый террор в Пермском крае оказал большое влияние на радикализацию взглядов Феликса Дзержинского. В первую очередь изменилось его отношение к офицерству. Теперь именно в нем он видел главную угрозу советской власти, и приказы о расстрелах бывших офицеров стали частыми в практике Ф. Э. Дзержинского на посту председателя ВЧК.

Ключевые слова: Гражданская война; 1918 г.; Ф. Э. Дзержинский; И. В. Сталин; Я. М. Свердлов; Я. Х. Петерс; «пермская катастрофа»; белый террор.

Сибирская армия Р. Гайды взяла Пермь 24 декабря 1918 г. Непосредственно штурмом города руководил генерал А. Н. Пепеляев. Это была крупнейшая победа белых в указанный период Гражданской войны: Третья Красная армия под командованием М. М. Лашевича была практически полностью разгромлена, победителям достались крупные запасы боеприпасов и продовольствия. Захваченными оказались важнейшие оружейные заводы - Пермские пушечные заводы в Мотовилихе (район Перми). Менялись ранее принятые стратегические решения. Главное командование Красной армии вынуждено было поменять не только направление наступления Второй армии с восточного на северное, но и отменить намеченное ранее передислоцирование Первой армии на Южный фронт, оставив ее на Восточном [Какурин, т. 2, с. 119]. Пермские события конца 1918 - начала 1919 г. оказали большое влияние на ход Гражданской войны, не только приостановив наступление красных войск на Восточном фронте, но и повлияв на ситуацию на ключевом Южном фронте. Эффект указанного поражения определил дальнейшее обозначение этих событий как «пермской катастрофы». Это определение ввели в оборот И. В. Сталин и Ф. Э. Дзержинский, направленные для выявления обстоятельств падения Перми. Понятие «катастрофа» применялось ими в отправленном В. И. Ленину 
по телеграфу отчете от 19 января 1919 г. и в отчете ЦК ВКП(б) и Совету Обороны 31 января 1919 г. Следует отметить, что Ленин ранее в телеграмме от 31 декабря 1918 г. писал Л. Д. Троцкому о катастрофическом положение в армии под Пермью.

Расследование пермских событий было поручено И. В. Сталину и Ф. Э. Дзержинскому, которым удалось в значительной степени выправить ситуацию. Политическим и военным обстоятельствам этих событий посвящен ряд последних исторических публикаций [Войтиков, 2013; Дубинин; Скипина, Московкин]. Однако в них в полной степени не раскрыто влияние этих событий на судьбы указанных деятелей. Между тем, «пермская катастрофа» оказала существенное влияние на дальнейшие взгляды и жизненный путь как Сталина, так и Дзержинского.

Ситуация в захваченном белыми регионе грозила распространиться на соседние территории, угрожая не только местной советской власти и населению, но и, что было более важно, существовала опасность разрушения северного участка Восточного фронта. Необходимо было в срочном порядке стабилизировать фронт, выявить причины поражения в декабрьских событиях с целью предотвращения новых. Этот вопрос обсуждался на заседании ЦК 30 декабря 1918 г. Уже 1 января 1919 г. ЦК РКП(б) и Совет Обороны образовали партийно-следственную комиссию в составе И. В. Сталина и Ф. Э. Дзержинского для выяснения причин сдачи Перми и принятия мер к восстановлению доминирования советской власти в этом районе. Делегирование указанных лиц не было случайным. Это не было, например, инициативой Ф. Э. Дзержинского, который намеревался в эти дни выехать в противоположном направлении на Западный фронт, посетив заодно родные места [Ратьковский, 2015, с. 17]. Не выявлено по документам и инициативы в данном вопросе со стороны И. В. Сталина. Обоих видных деятелей большевистской партии делегировал Я. М. Свердлов, решая этим сразу несколько задач. Помимо необходимости расследования обстоятельств «пермской катастрофы», Свердлов добился удаления из Москвы Сталина, своего оппонента по многим вопросам [Войтиков, 2015, с. 30-45; Войтиков, 2014, с. 24-43]. Отъезд Дзержинского также отвечал интересам Свердлова. Для него было важным временное замещение Дзержинского на посту руководителя ВЧК Я. Х. Петерсом, с которым он сработался в период отставки Дзержинского летом 1918 г. и его же более поздней осенней поездки (по инициативе того же Свердлова) в Швейцарию и Германию. Контроль Свердлова над ВЧК, таким образом, значительно усиливался. Эти обстоятельства и определили события последующего январского расстрела великих князей в Петропавловской крепости, несмотря на принятое В. И. Лениным решение об их освобождении [Ратьковский, 2005 , с. 270]. Следствием командировки Дзержинского явилось также ослабление охраны Ленина в этот период, результатом чего стал возможным январский инцидент с бандой Я. Кошелькова, когда руководитель Советского государства едва не стал жертвой московских 
преступников. В любом случае удаление Сталина и Дзержинского усиливало позиции Свердлова.

Тем не менее, сама ситуация на пермском направлении была критической и требовала немедленного разрешения. Поэтому туда были посланы люди хотя и «неудобные» Свердлову, но, безусловно, имевшие уже сложившуюся репутацию решительных деятелей. Сталину и Дзержинскому были даны чрезвычайные полномочия для наведения порядка в Пермском регионе. Они имели возможность требовать объяснений от всех местных властей, вплоть до смещения должностных лиц и придания виновных суду военно-революционного трибунала [Ф. Э. Дзержинский - председатель ВЧК-ОГПУ, с. 95]. Контролируя процесс и определяя его дальнейшее развитие, Свердлов отправил телеграмму Уральскому обкому РКП(б) с постановлением о его роспуске и назначении партийно-следственной комиссии Сталина-Дзержинского для расследования обстоятельств падения Перми.

Поездка воспринималась обоими деятелями как срочная, не допускающая ни малейшего промедления. Характерно, что когда 3 января 1919 г. при отправке поезда с Ярославского вокзала вагон был подан несвоевременно, они незамедлительно связались по этому поводу с Лениным [Владимир Ильич Ленин, с. 399].

Наделенные ЦК чрезвычайными полномочиями в районе Третьей и Второй армий, Сталин и Дзержинский 5 января 1919 г. прибыли в Вятку. И для Сталина, и для Дзержинского это были знакомые места, где они когда-то отбывали ссылку. В частности, для Дзержинского Вятка была первым местом его ссылки [Ратьковский, 2013, с. 53-72].

Уже в день прибытия в Вятку они отправили в Москву телеграмму, в которой говорилось о предварительных итогах:

Председателю Совета Обороны товарищу Ленину.

Расследование начато. О ходе расследования будем сообщать попутно. Пока считаем нужным заявить вам об одной не терпящей отлагательства нужде III армии. Дело в том, что от III армии (более 30 тысяч человек) осталось лишь около 11 тысяч усталых истрепанных солдат, еле сдерживающих напор противника. Присланные Главкомом части ненадежны, частью даже враждебны к нам и нуждаются в серьезной фильтровке. Для спасения остатков III армии и предотвращения быстрого продвижения противника до Вятки (по всем данным, полученным от командного состава фронта и III армии, эта опасность совершенно реальна) абсолютно необходимо срочно перекинуть из России в распоряжение командарма по крайней мере три совершенно надежных полка. Настоятельно просим сделать в этом направлении нажим на соответствующие военные учреждения. Повторяем: без такой меры Вятке угрожает участь Перми, таково общее мнение причастных к делу товарищей, к которому мы присоединяемся на основании всех имеющихся у нас данных.

Сталин.

Ф. Дзержинский.

5 января 1919 г., Вятка. 8 часов вечера [Сталин, Дзержинский, с. 186-189]. 
В Вятке комиссия первоначально разместилась в доме на улице Ленина ${ }^{1}$, позднее в ночь на 7 января выехав в Глазов, в штаб Третьей армии, который размещался в здании мужской гимназии. Переезд был вызван необходимостью переформирования и чистки указанной армии.

Работа комиссии велась по нескольким направлениям. Одним из важнейших вопросов было выявление персональной ответственности за «пермскую катастрофу» в целом и вины за отдельные мероприятия (например, неосуществленный подрыв моста, отсутствие разведчиков и т. д.). Эти вопросы были намечены Дзержинским и Сталиным еще по выезду из Москвы и уточнялись по приезду [Сталин, Дзержинский, с. 186-189]. Решение этих вопросов потребовало их переезда в Глазов, в штаб Третьей армии. И Сталин, и Дзержинский критично воспринимали деятельность М. М. Лашевича на посту командующего Третьей армии, вновь и вновь выявляя степень его провального участия в событиях. Помимо этого, они проводили аресты комсостава Третьей армии [Дубинин, с. 14-15]. В основном эти аресты коснулись снабженцев, среди которых были выявлены не только небрежность и бездеятельность, но и пьянство, другие должностные преступления, результатом чего было оставление противнику большого количества грузов [Ф. Э. Дзержинский - председатель ВЧК-ОГПУ, с. 97-98].

Неделя энергичной работы в Вятке и Глазове позволила комиссии сформулировать основные выводы о причинах падения Перми. 13 января 1919 г. в Москву в ЦК был направлен «Краткий предварительный отчет о ходе расследования причин сдачи Перми и особенно о мерах, намеченных комиссией для восстановления положения на участке 3-й армии». Уже на следующий день ознакомившийся с текстом телеграммы и намеченными мерами Ленин телеграфировал в Глазов:

Получил и прочел первую шифрованную депешу. Очень прошу вас обоих лично руководить исполнением намеченных мер на месте, иначе нет гарантии успеха. Ленин [Ленин, т. 50, с. 243].

Вторым вопросом, которым занималась комиссия, была чистка местных партийных и советских органов. Помимо удаления «виновного и лишнего элемента», эта работа могла решить задачу насыщения партийными кадрами Третьей армии. 18 января 1919 г. И. В. Сталин и Ф. Э. Дзержинский с этой целью выезжают из Глазова в Вятку. На следующий день они выступили на объединенном заседании уральских и вятских партийных и советских организаций. Было объявлено о создании Вятского военно-революционного комитета и о масштабной мобилизации партийных кадров в армию. В этот же

${ }^{1}$ Первоначально улица носила название Вознесенской в связи с находившимся здесь Вознесенским кафедральным собором, с 1895 г. в честь Николая II называлась Николаевской, а 21 сентября 1918 г. Вятский горсовет постановил переименовать ее в улицу Ленина. 
день они провели совещание представителей Народного комиссариата путей сообщения, отдела военных сообщений Третьей армии и других организаций, посвященное разгрузке вятского железнодорожного узла. Одним из вопросов, рассмотренных в этот день, был вопрос о предоставлении управлению снабжения Третьей армии 10 тысяч пудов мороженого мяса из обнаруженных на складах Вятского губкома 30 тысяч пудов (об этом Сталин и Дзержинский телеграфировали Ленину 16 января из Глазова) [Ф. Э. Дзержинский - председатель ВЧК-ОГПУ, с. 98]. Проведенная работа позволила составить общее представление о ситуации в регионе и отчитаться в этот же день перед Лениным о мерах, принятых для укрепления фронта и тыла Третьей армии.

На следующий день Сталин из Вятки связался с Лашевичем, сообщив ему (по результатам прошедшего накануне совещания) о предстоящем улучшении снабжения Третьей армии со складов Вятки и «складов с колес» в ближайшие дни [Дубинин, с. 15]. Проведенные мероприятия позволили комиссии 21января выехать обратно в Глазов, где она находилась до 25 января 1919 г., когда Дзержинский и Сталин вернулись в Вятку. 27 января они выехали из Вятки в Москву, и 29 января уже были на месте.

В этот же день они предоставили Ленину подробный отчет о причинах падения Перми и о мерах, принятых для восстановления положения в районе Третьей армии. В частности, они указывали на отсутствие резервов (как людских, так и материальных), на засорение Третьей армии классово чуждыми элементами, на материальное обеспечение красноармейцев. Плохое материальное снабжение армии и вследствие этого нежелание красноармейцев идти в бой подтверждают и современные архивные исследования [Скипина, Московкин, с. 104].

Среди выявленных комиссией причин «пермской катастрофы» были и ошибки, допущенные как Всероссийским бюро военных комиссаров, так и Реввоенсоветом республики, выразившиеся в отрыве от боевой деятельности и жизни, от нужд Красной армии. В докладе «досталось» как РВС Восточного фронта, так и косвенно главе РВСР Л. Д. Троцкому. Результаты расследования были оценены Лениным положительно.

Пермская экспедиция имела для Дзержинского и Сталина важные последствия. Помимо налаживания товарищеских отношений, что в дальнейшем будет иметь принципиальное значение, оба большевика убедились в едином для них мнении о необходимости жесткого контроля над бывшими офицерами. В этом их убеждал опыт белого террора в регионе.

Захват Перми сопровождался традиционным «наведением порядка» новыми властями. В городе и его окрестностях незамедлительно начался жесточайший белый террор. На Мотовилихинском заводе (захвачен 8-м Бийским полком группы генерала Б. М. Зиневича) было расстреляно свыше ста рабочих [Гражданская война, с. 365]. 
Некоторые части белых, например, штурмовой батальон Урбановского, пленных не брали принципиально. В частности, на Базарной площади в Нытве его подчиненные закололи штыками более сотни пленных красноармейцев, а также местных жителей, заподозренных в сочувствии советской власти. Массовые расстрелы в самой Перми проходили на льду Камы. Свою лепту в расправы внесла белая контрразведка, расположившаяся в здании бывшего духовного училища (угол Покровской и Оханской улиц). Позднее в подвальном помещении этого здания при ремонте в 1923 г. под слоем земли были обнаружены многочисленные останки людей [Аборкин; Коробейников; Курамшина].

Дополняют сведения о белом терроре в Перми и ее окрестностях материалы, размещенные в документальном сборнике «Гражданская война в Прикамье». В Покровской волости при населении в четыре тысячи человек было убито 35 человек (почти каждый сотый), многие выпороты. В Альняшинской волости расстреляно пять человек, из них один красноармеец-коммунист, выданный родственниками. В этой же волости действовал контрреволюционный повстанческий отряд под командованием офицера Балабанова, жертвами которого стали около 350 коммунистов и сочувствующих им. Также в сборнике приводятся более поздние данные местной ЧК о белом терроре:

Хотя точный подсчет и не сделан по всей губернии, но по статистическим данным, которые имеются в Губчека, можно сказать, что расстреляно белыми 2558 человек, отпорото 1677, арестовано 5471, пострадали имущественно 5471 [Гражданская война в Прикамье, с. 349, 367-368, 428-429].

Есть данные и по отдельным городам края. Например, в Майкоре было расстреляно более ста человек. Согласно воспоминаниям, эти расстрелы часто проходили с изощренной жестокостью. Так, жителю деревни Азово Конону Якимову сначала отрубили руки, потом ноги, изрубили тело шашками, а уж потом добили его выстрелами из винтовок и наганов [Сайт города Майкора].

Массовые расстрелы проходили в Оханске. Перед отступлением белыми, согласно запискам председателя Оханской ЧК, было расстреляно 42 человека, в том числе бывшие члены исполкома Некрасов и Старцев [Оханск.ru]. В Соликамске был зарублен командир продотряда коммунист А. В. Логинов, расстрелян начальник милиции И. А. Дегтярников и 28 других жителей города, обвиненных следственной комиссией «в сотрудничестве с советской властью» [Капцугович, с. 85].

По официальным советским данным, в Нижнетагильском и Надеждинском районах от рук колчаковцев пострадало свыше 10 тысяч человек [Процесс над колчаковскими министрами, с. 23]. Все эти расстрелы шли помимо официальной гражданской власти, протесты которой игнорировались [Домовитая, с. 42-50]. И если для Сталина это было закреплением его царицынского опыта, то для Дзержинского 
полученные сведения о ряде измен, а главное, о массовых казнях в Пермском крае имели важные последствия для изменения его взглядов на карательную политику по отношению к офицерству. До Пермской экспедиции Дзержинский не выделял бывших офицеров в Советской России как изначально враждебный элемент, подлежащий безусловному уничтожению. В ряде дел лета-осени 1918 г. он допускал смягчение мер наказания для его представителей в случае отсутствия явной вины. Например, офицеры, арестованные в ходе весеннее-летнего расследования дела «Союза защиты Родины и свободы», не были расстреляны в период председательства в ВЧК Дзержинского. Эта участь их постигла, когда его летом заменил на этом посту Я. Петерс [Ратьковский, 1995, c. 95, 105]. При этом среди расстрелянных савинковцев позднее оказался и А. А. Виленкин, оправданный ранее Дзержинским, но казненный Петерсом в тот период, когда Дзержинского не было в Москве (он находился в Петрограде, расследуя обстоятельства убийства М. С. Урицкого 30 августа 1918 г.).

После января 1919 г. позиция Дзержинского в отношении к офицерству стала более жесткой и непримиримой и уже не исключала массовых превентивных расправ над ним. Дальнейшие события, произошедшие после освобождения города красными войсками, возможно, только убедили Дзержинского в его внутренней правоте. Согласно сохранившейся в московском архиве РЦХИДНИ июльской телеграмме члена РВС Восточного фронта Н. И. Муралова А. И. Рыкову из освобожденной 1 июля 1919 г. красными войсками Перми, белые успели перед оставлением города сжечь и потопить свыше 50 пароходов с продовольствием и нефтью. На баржах сожгли около тысячи пленных красноармейцев и выпустили из тюрем всех уголовников, около двух тысяч политзаключенных (красных) попытались переправить в свой тыл, но белый конвой их отпустил [Павлюченков, с. 126; РЦХИДНИ, л. 1-3].

Из Москвы массовый террор в Перми виделся большевистским лидерам не просто как следствие террора противника, а как проявление «людоедской сущности» белого движения, белого офицерства [Бухарин]. В этом же был теперь убежден и Ф. Э. Дзержинский, находившийся на пермском участке фронта в начале 1919 г. Итогом пермской командировки стала моральная готовность Дзержинского к массовым репрессиям против офицерства, включая принятие им списочной расстрельной практики в деятельности ВЧК.

\section{Список литературы}

Аборкин В. За что и как боролся Колчак? // Вечерняя Пермь. 1991. 1 марта.

Бухарин Н. «Людоеды» // Беднота. 1919. 10 июля.

В. И. Ленин : Биографическая хроника : в 12 т. М. : Изд-во полит. лит-ры, 19701982. T. 6.

Войтиков C. C. «Пермская катастрофа» Льва Троцкого и Якова Свердлова // Военно-исторический журнал. 2013. № 8. С. 19-25.

Войтиков С. С. «Председатель ЦК»: Я. М. Свердлов в политической борьбе 1918 - 
начала 1919 года // Российская история. 2014. С. 24-43.

Войтиков С. С. И. В. Сталин против Я. М. Свердлова: Осень 1918 // Новейшая история России. 2015. № 3. С. 30-45.

Гражданская война в Прикамье : Май 1918 - январь 1920 г. : сб. докл. Пермь : Агентство «Стиль-МГ», 2008. 503 с.

Гражданская война и военная интервенция в СССР : энциклопедия. М. : Советская энциклопедия, 1987. 704 с.

Домовитая П. Я. Проблема «двоевластия» на Урале в условиях режима А. В. Колчака (декабрь 1918 г. - апрель 1919 г.) // Вестн. Перм. ун-та. Сер. «История». 2014. № 2. С. 42-50.

Дубинин Д. В. Участие Сталина в ликвидации последствий Пермской катастрофы // Исторические науки. 2009. № 6. С. 13-17.

Записки председателя Оханской ЧК // Оханск.ru [сайт]. URL: http://ohansk.ru/ history/882/10.htm (дата обращения: 01.03.2016).

Какурин Н. Е. Как сражалась революция : в 2 т. 2-е изд., уточн. М., 1990.

Капиугович И. С. Прикамье в огне Гражданской войны. Пермь, 1969. 130 с.

Коробейников В. Колчак в Перми // Вечерняя Пермь. 1994. 3 марта.

Курамшина А. В. Повседневная жизнь рабочих Прикамья при политическом режиме адмирала А. В. Колчака // Гражданская война на востоке России : Пермь, ноябрь 2008 : материалы интернет-конф. // URL: http://www.permgani.ru/publikatsii/ konferentsii/grazhdanskaya-vojna-na-vostoke-rossii.html (дата обращения: 01.03.2016).

Майкор [официальный сайт]. URL: http://maikor.ru/press/17 (дата обращения: 01.03.2016).

Павлюченков С. А. Военный коммунизм в России: власть и массы. М. : Рус. книгоиздат. товарищество - История, 1997. 272 с.

Процесс над колчаковскими министрами : Май 1920 / под ред. акад. А. Н. Яковлева ; отв. ред. В. И. Шишкин. М. : Междунар. фонд «Демократия», 2003. 672 с.

Ратьковский И. С. Дзержиново в судьбе «Железного Феликса» // Новейшая история России. 2015. № 3. С. 8-21.

Ратьковский И. С. Первая ссылка Феликса Дзержинского // Труды исторического факультета Санкт-Петербургского университета. 2013. № 14. С. 53-72.

Ратьковский И. С. Первый год деятельности Петроградской ЧК (март 1918 - март 1919) // Проблемы новейшей истории России : сб. ст. к 70-летию Г. Л. Соболева. СПб. : Изд-во СПбГУ, 2005. С. 252-271.

РЦХИДНИ. Ф. 2. Оп.1. Д. 10493. Л. 1-3.

Скипина И. В., Московкин В. В. Роль человеческого фактора в военном противостоянии на Урале зимой 1918-1919 гг. // Теория и практика общественного развития. 2014. № 10. С. 103-105.

Сталин И. В. Дзержинский Ф. Э. Письмо к В. И. Ленину с Восточного фронта 5 января 1919 г. // Сталин И. В. Сочинения : в 13 т. М. : ОГИЗ ; Гос. изд-во политич. лит., 1947. Т. 4. С. 186-189.

Ф. Э. Дзержинский - председатель ВЧК-ОГПУ : 1917-1926 / сост. А. А. Плеханов, А. М. Плеханов. М. : Международный фонд «Демократия»; Материк, 2007. 872 с.

\section{References}

Aborkin, V. (1991). Za chto i kak borolsya Kolchak? [What for and how Did Kolchak Fight?]. In Vechernyaya Perm', March 1.

Bukharin, N. (1919). “Lyudoedy" [Cannibals]. In Bednota, July 10.

Domovitaya, P. Ya. (2014). Problema "dvoevlastiya" na Urale v usloviyakh rezhima A. V. Kolchaka (dekabr' 1918 g. - aprel' 1919 g.). [The Problem of Diarchy in the Urals under A.V. Kolchak's Regime (December 1918 - April 1919)]. In Vestnik Permskogo universiteta. Seriva "Istoriya", 2, pp. 42-50.

Dubinin, D. V. (2009). Uchastie Stalina v likvidatsii posledstviy Permskoy katastrofy [Stalin's Participation in the Perm Catastrophe Consequences Liquidation]. In Istoricheskie nauki, 6, pp. 13-17.

Grazhdanskaya voyna v Prikam'e. May 1918 - yanvar' $1920 \mathrm{gg}$. Sb. dok-v [The Civil War in Prikamye. May 1918 - January 1920]. (2008). 503 p. Perm, Agentstvo "Stil'-MG".

Grazhdanskaya voyna i voennaya interventsiya v SSSR. Entsiklopediya [The Civil War and Military Intervention in the USSR. An Encyclopaedia]. (1983). 704 p. Moscow, Sovetskaya entsiklopediya. 
Kakurin, N. E. (1990). Kak srazhalas' revolyutsiya [How the Revolution Advanced]. Vol. 2. 1919-1920. $2^{\text {nd }}$ ed. 431 p. Moscow, Politizdat.

Kaptsugovich, I. S. (1969). Prikam'e v ogne grazhdanskoy voyny [Prikamye in the Flames of the Civil War]. 130 p. Perm, Permskoe knizhnoe izdatel'stvo.

Korobeynikov, V. (1994). Kolchak v Permi [Kolchak in Perm]. In Vechernyaya Perm', March 3.

Kuramshina, A. V. (2008). Povsednevnaya zhizn' rabochikh Prikam'ya pri politicheskom rezhime admirala A. V. Kolchaka [Prikamye Workers' Everyday Life under the Political Regime of Admiral A.V. Kolchak]. In Materialy internet-konferentsii "Grazhdanskaya voyna na Vostoke Rossii. Perm”. Noyabr' 2008. URL: http:/www.permgani.ru/publikatsii/ konferentsii/grazhdanskaya-vojna-na-vostoke-rossii.html (mode of access: 01.03.2016).

Lenin, V. I. (1970). Polnoe sobranie sochineny v 55 t. [Complete Works in 55 Vols.]. $5^{\text {th }}$ ed. Vol. 50. Pis'ma. Oktyabr' 1917 - iyun' 1919. Moscow, Izdatel'stvo Politicheskoy literatury.

Maykor [ofitsial'nyy sayt]. URL: http://maikor.ru/press/17 (mode of access: 01.03.2016).

Pavlyuchenkov, S. A. (1997). Voennyy kommunizm v Rossii: vlast' $i$ massy [Military Communism in Russia: Power and the Large Public]. 272 p. Moscow, Russkoe knigoizdatel'skoe tovarishchestvo - Istoriya.

Plekhanov, A. A. \& Plekhanov, A. M. (Comp.). (2007). F. E. Dzerzhinsky-predsedatel' VChK-OGPU. 1917-1926 [F.E. Dzerzhinsky - Chairman of the All-Russian Cheka-OGPU]. 872 p. Moscow, Mezhdunarodnyy fond "Demokratiya", Materik.

Rat'kovsky, I. S. (2015). Dzerzhinovo v sud'be "Zheleznogo Feliksa" [Dzerzhinowo in the Fate of the "Iron Felix"]. In Noveyshaya istoriya Rossii, 3, pp. 8-21.

Rat'kovsky, I. S. (2013). Pervaya ssylka Feliksa Dzerzhinskogo [Felix Dzerzhinsky's First Exile]. In Trudy istoricheskogo fakul'teta Sankt-Peterburgskogo universiteta, 14, pp. 53-72.

Rat'kovsky, I. S. (2005). Pervyy god deyatel'nosti Petrogradskaya ChK (mart 1918 mart 1919) [The First Year of the Petrograd Cheka Operation (March 1918 - March 1919)]. In Problemy noveyshey istorii Rossii. Sb. st. k 70-letiyu G. L. Soboleva (pp. 252-271). Sankt Petersburg, Izdatel'stvo SPbGU.

Rossiysky Tsentr khraneniya i izucheniya dokumentov noveyshey istorii [The Russian Centre for the Storage and Study of Modern History Documents]. Stock 2. List1. Dossier10493. Leaf 1-3.

Sayt goroda Maykora [Website of the Town of Maykor]. URL: http://maikor.ru/press/17 (mode of access 1.03.2016).

Skipina, I. V. \& Moskovkin, V. V. (2014). Rol' chelovecheskogo faktora v voennom protivostoyanii na Urale zimoy 1918-1919 gg. [The Role of the Human Factor in the Military Confrontation in the Urals, Winter of 1918-1919]. In Teoriya i praktika obshchestvennogo razvitiya, 10 , pp.103-105.

Stalin, I. V. \& Dzerzhinsky, F. E. (1947). Pis'mo k V. I. Leninu s Vostochnogo fronta 5 yanvarya $1919 \mathrm{~g}$. [A Letter to V.I. Lenin from the Eastern Front as of January 5, 1919]. In Stalin, I. V. Sochineniya v 13 t.. Vol. 4, pp. 186-189. Moscow, OGIZ; Gosudarstvennoe izdatel'stvo politicheskoy literatury.

Vladimir Il'ich Lenin: Biograficheskaya khronika [A Biographical Chronicle]. (1975). Vol. 6. 666 p. Moscow, Politizdat.

Voytikov, S. S. (2013). "Permskaya katastrofa" L'va Trotskogo i Yakova Sverdlova [The Perm Catastrophe of Leon Trotsky and Yakov Sverdlov]. In Voenno-istorichesky zhurnal, 8, pp. 19-25.

Voytikov, S. S. (2014). "Predsedatel' TsK”: Ya. M. Sverdlov v politicheskoy bor'be 1918 - nachala 1919 goda [Chairman of the Central Committee: Ya. M. Sverdlov in the Political Struggle of 1918 - Early 1919]. In Rossiyskaya istoriya, 1, pp. 24-43.

Voytikov, S. S. (2015). I. V. Stalin protiv Ya. M. Sverdlova. Osen' 1918 [J. V. Stalin against Ya.M. Sverdlov. Autumn of 1918]. In Noveyshaya istoriya Rossii, 3, pp. 30-45.

Yakovlev, A. N. \& Shishkin, V. I. (Eds.). (2003). Protsess nad kolchakovskimi ministrami. May 1920 [The Trial of Kolchak's Ministers: May, 1920]. 672 p. Moscow, Mezhdunarodnyy fond "Demokratiya".

Zapiski predsedatelya Okhanskoy ChK [Notes of Okhansk Cheka Chairman]. URL: http://ohansk.ru/history/882/10.htm (mode of access 1.03.2016). 